\title{
UNMANNED AERIAL VEHICLE PHOTOGRAMMETRY AND 3D MODELING APPLIED TO VIRTUAL RECONSTRUCTION OF AN ARCHAEOLOGICAL SITE IN THE BRONCE AGE
}

\author{
F. Carvajal-Ramírez ${ }^{1 *}$, A.D. Navarro-Ortega ${ }^{2}$, F. Agüera-Vega ${ }^{1}$, P. Martínez-Carricondo ${ }^{3}$ \\ ${ }^{1}$ Department of Engineering, Mediterranean Research Center of Economics and Sustainable \\ Development (CIMEDES), University of Almeria, (Agrifood Campus of International Excellence, ceiA3). La Cañada de San \\ Urbano, s/n. 04120 Almería, Spain - (carvajal, faguera)@ual.es \\ ${ }^{2}$ Department of Geography, History and Humanities, Researching group HUM-741 The Legacy of Antiquity. University of Almeria \\ La Cañada de San Urbano, s/n. 04120 Almería, Spain - annad.navarro@ gmail.com \\ ${ }^{3}$ Peripheral Service of Research and Development based on Drones, University of Almeria. La Cañada de San Urbano, s/n. 04120 \\ Almería, Spain - pmc824@ual.es
}

Commission II, WG II/8

KEY WORDS: Unmanned Aerial Vehicle Photogrammetry, Bronze Age, 3D modelling

\begin{abstract}
:
The risk of disappearing of cultural heritage of archaeological sites is directly related to the protection level by the corresponding administrations. This is the case of Cortijo Nuevo, an archaeological site with no known precedents in the Iberian Peninsula in the Bronze Age.

The recent development of Unmanned Aerial Vehicles (UAV) used as platform carrying digital cameras, let to adapt the well-known classical Photogrammetry technique, in conjunction with Structure from Motion (SfM) and Multi View Stereo (MVS) algorithms, for very high accurate surveying of the terrain.

In this work, several digital cartographic products including point cloud, Digital Elevation Model (DEM) and orthoimage were obtained from UAV-Photogrammetric flight with the purpose of document and virtual reconstruction of a damaged archaeological site. All the technical prescriptions of the flight and photogrammetric project were designed for accurately representing the state of the terrain in both epochs, current and previous to damage. The quality control for quantify planimetric and altimetric errors, based on 33 ground control points, showed $\mathrm{RMSE}_{\mathrm{xy}}=0.0246 \mathrm{~m}, \mathrm{RMSE}_{\mathrm{z}}=0.0262 \mathrm{~m}$ and the total error sum of $0.0359 \mathrm{~m}$. An integration of virtual 3D archaeological structures with the obtained terrain models was carried out through augmented reality technology, based on the information obtained in this work.
\end{abstract}

\section{INTRODUCTION}

Cultural heritage conservation in archaeological sites where the elements has been damaged or even destroyed can be carried out through virtual reconstruction (Achille et al., 2015; De Reu et al., 2013; Hendrickx et al., 2011) based on UAV-Photogrammetry (Chiabrando et al., 2011; Mesas-Carrascosa et al., 2016; MozasCalvache et al., 2012; Wolf and Dewitt, 2014) and augmented reality technology (Martínez-Carricondo et al., 2019).

With the recent development of scientific applications of Unmanned Aerial Vehicles (UAV), new possibilities of archaeologic studies and conservation works have appeared. Furthermore, archaeologists and experts can formulate their hypothesis based on 3D reconstructions and augmented reality, about geometry and possible functions of structures in damaged or destroyed archaeological site. For more detailed information about UAV Photogrammetric applications, see (Eisenbeiß et al., 2009; Sauerbier and Eisenbeiss, 2010)

This is the case of Cortijo Nuevo, a Bronce Age archaeological site located in southern Spain, currently almost destroyed by deliberated man actions and wrong protection policies (CarvajalRamírez et al., 2019; Gusi et al., 2010). In previous archaeological campaigns were recorded a set of mound structures made of stones, distributed in a systematic way according to the contours levels of the terrain, and interconnected one each other. Due to the scarce previous information, it is not clear what the function of these structures was, originally covered by vaults made of stone too. According to (Carvajal-Ramírez et al., 2019) likely, the complex was used for some kind of fish transformation or conservation related to maritime traffic flow. It is located at a natural drainage area close to the coastline of Mediterranean Sea. In this province some evidences of Roman establishment, an Islamic city with necropolis and fortress have been documented.

The settlement of Cortijo Nuevo belongs to second century BC and the Barranquete Necropolis is $2 \mathrm{~km}$ far away. The complex was discovered in 1975 when the owner of the terrain started works to transform an old agricultural exploitation. Two years after the local government promoted an archaeological campaign in which no cartographic information was generated. Some of the structures were excavated and documented with the final consequence of an Official Asset of Cultural Interest, in 1987.

According to some indirect evidences, unauthorized earth moving works were carried out around 1994, which were corroborated at the second official archaeological campaign in 1997. The great degradation of the elements in the site joined to the rejection of the Official Asset of Cultural Interest by a court in 2005. From this time to now, continuous unauthorized modifications of the terrain has been done with the consequent loss of information and cultural heritage.

Taking into account the actual site conservation state, and the potential of UAV-Photogrammetry for documentation archaeological sites (Ortiz et al., 2013; Sauerbier and Eisenbeiss, 2010; Verhoeven, 2009; Verhoeven et al., 2009), a photogrammetric UAV flight was designed with the aim of combining different source of information including both

\footnotetext{
* Corresponding author
} 
archaeological campaigns and Digital Elevation Models (DEM) for developing a 3D virtual reconstruction.

The aim of this work was to design an UAV Photogrammetric flight, carry out the corresponding surveying campaign for georreferencing the resulting DEM and implement the corresponding photogrammetric project, all of them with the technical prescriptions for integration in a virtual 3D model. Furthermore, the geometric errors of the products were estimated in order to determine the applicability of DEM for virtual reconstruction and augmented reality of Cortijo Nuevo archaeological site.

\section{MATERIALS AND METHODS}

\subsection{Study area}

Cortijo Nuevo is located in Almeria province, southern Spain, with geographic coordinates $36^{\circ} 49^{\prime} 24.5$ ' ' N latitude, 2213 ' 59 " W longitude. The natural environ is partially occupied by greenhouses and some disperse farms and small buildings (Figure 1).

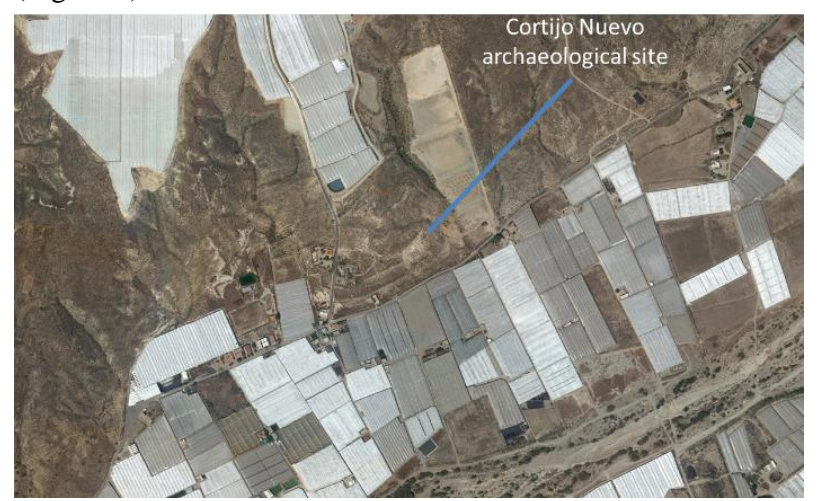

Figure 1. Current state of the study area, in a greenhouse intensive agriculture zone

The archaeological site was described by (Galea et al., 1977) as a network of structures made of stones interconnected by channels aligned with the contour of the original terrain (Figure 2).

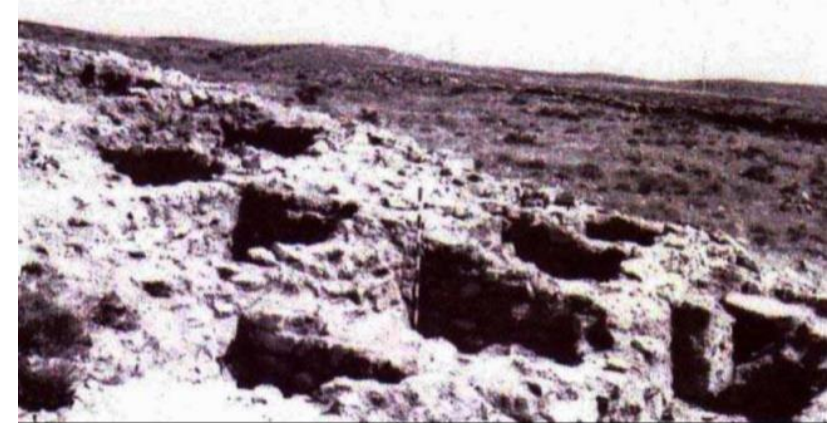

Figure 2. Network of structures made of stone, documented in the archaeological campaign in 1979, actually destroyed

\subsection{UAV System}

The microdrones md4-200 UAV rotatory-wing quadcopter with a maximum payload of $200 \mathrm{~g}$ was used to carry a Pentax Optio A40 digital camera, with 12 megapixels stabilized by an electronically controlled gimbal. The UAV was remotely controlled by flight routes programmed. The navigations system was based on Global Navigation Satellite System (GNSS) device that let to UAV to stablishing at waypoints. Camera orientation and shutting actions was also programmed from optimizing the photogrammetric overlap between images. The inertial data at waypoints were saved to be used in the photogrammetric process. Flight routes and other flight parameters were designed and implemented to the UAV system using mdCockpit Standard Edtion v. 2.8.0.6 (Microdrones, 2018).

\subsection{Surveying campaign}

In order to assign a Universal Coordinate System to the resulting 3D-models and control the quality the graphic products, a surveying campaign was carried out. A Trimble R6 GPS couple of devices in Real-Time Kinematic mode was used to measure a set of 46 target control points, 13 of them were used for orientation assessment in the photogrammetric project (control points) and the rest for quality control (check points). The distribution of the control points and check point was according to (Agüera-Vega et al., 2017; Carvajal-Ramírez et al., 2016; Martínez-Carricondo et al., 2018). Both control points and check points were materialized by target of A4 normalized size (Figure 3 ), for easy identification in the images.

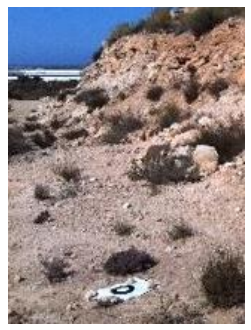

Figure 3. A4 size target point materializing control points and check points

The data collected in the surveying campaign was post-processed with Trimble Geomatics Office (Trimble-Inc., 2018) and was referred to the official reference system in Spain.

\subsection{Flight planning}

Flight routes of the UAV was planned and programmed for autonomous operation, covering a target area close to $2.2 \mathrm{ha}$. The high of flight was $80 \mathrm{~m}$ over the ground level, the flight time planned was close to $21 \mathrm{~min}$ and the total flight route was 1200 $\mathrm{m}$ in six paths separated by a distance of $12 \mathrm{~m}$, each with 11 waypoints (Figure 4).

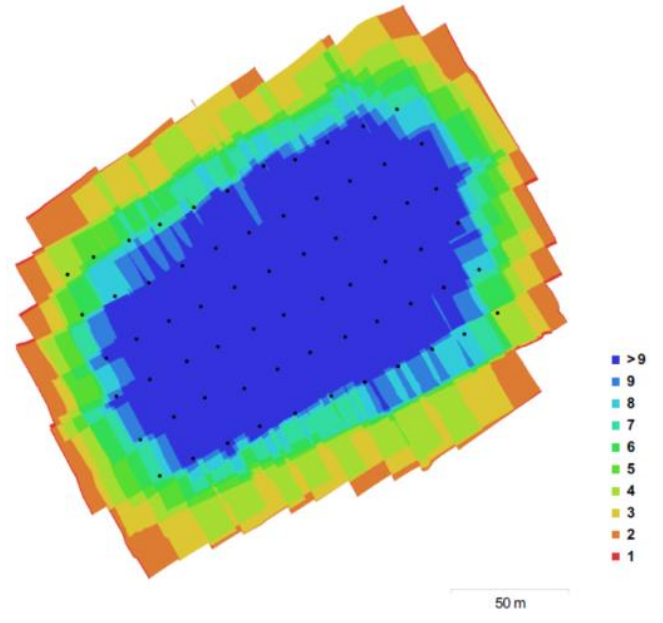

Figure 4. Distribution of waypoints programmed in the flight route and image overlap 
The taking-off point was located at the higher point of the site and both overlaps longitudinal and transversal were close to $75 \%$ between consecutives images and paths.

\subsection{Photogrammetric algorithm}

According to previous works (Sauerbier and Eisenbeiss, 2010), the Structure from Motion (SfM) (Fonstad et al., 2013) and Multi-View Stereopsis (MVS) (Furukawa and Ponce, 2010) algorithms have demonstrated useful for archaeological documentation and material detection purposes.

These algorithms present some differences respect to classical close range photogrammetry that let to use non-metric cameras carried by UAV, characterized by variations of scale and orientation between images.

SfM strategy lets to reconstruct 3D terrain geometry from the camera motion by matching features on multiple images of a scene taken in an unstructured way.

The photogrammetric project was carried out with Agisoft PhotoScan Professional Edition v. 1.2.2 (Agisoft, 2018), a lowcost software that implements SfM algorithm.

\section{RESULTS AND DISCUSION}

A total of 66 images were obtained from the UAV flight and the control points coordinates measured in the surveying campaign were referred to the Universal Transverse Mercator UTM coordinate system, located in northern hemisphere, zone 30 . It was used the European Datum 1950 with the geoidal model Ibergeo. Both images and control points were the input data for the photogrammetric project.

\subsection{Photogrammetric results and products}

The use of non-metric cameras in photogrammetric projects demands to accomplish a previous calibration process to estimate the internal orientation parameters (Perez et al., 2011; Wolf and Dewitt, 2014). Focal length, format size of the sensor and lens distortions functions must be known in order to represent the 3D geometry of the terrain based on 2D images. Table 1 shows the resulting camera parameters after field calibration postprocessing carried out in this work.

\begin{tabular}{|l|c|c|}
\hline Focal length $(\mathrm{mm})$ & \multicolumn{2}{|c|}{7.934} \\
\hline Format size $(\mathrm{mm})$ & \multicolumn{2}{|c|}{$7.196 \times 5.397$} \\
\hline Principal point $(\mathrm{mm})$ & \multicolumn{2}{|c|}{$3.587,2.565$} \\
\hline \multirow{2}{*}{ Radial distortion } & K1 & -0.18711 \\
function parameters & K2 & 0.109743 \\
& K3 & 0.0895092 \\
\hline Decentring distortion & P1 & -0.00020379 \\
function parameters & P2 & -0.00353266 \\
\hline
\end{tabular}

Table 1. Pentax Optio A40 calibration report

The first step in the photogrammetric project was to align all the images according to the external orientation parameter including orientation and positon of the UAV through the flight (Figure 5). SfM algorithm lets to bundle block adjustment of collinearity equations, and the 3D model is unscaled and referred to a relative reference system. The RMS reprojection error was $0.1880 \mathrm{~m}$ (0.964 pixel) obtained of the disperse point cloud of 35.610 points automatically generated by SfM algorithm.

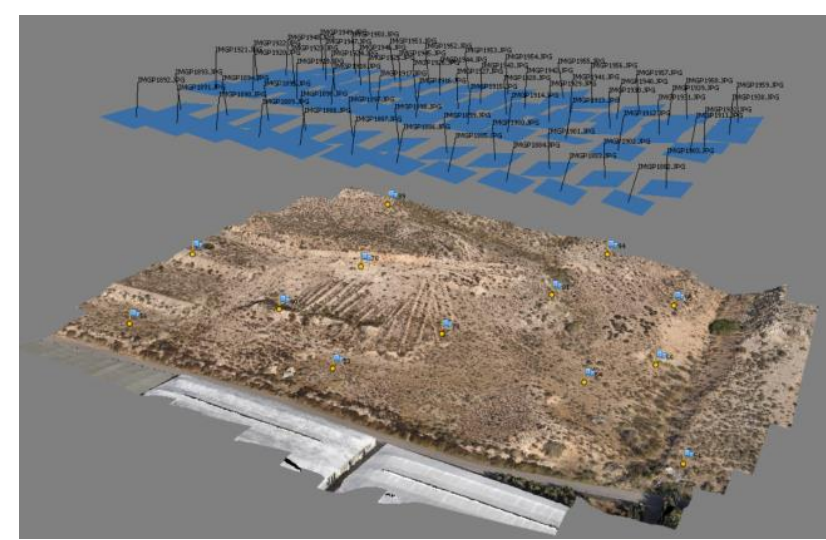

Figure 5. Unoriented and unscaled 3D photogrammetric block resulting from bundl ajustment process. Position and orientation of the 66 images are represented by blue squared and control point by flags

After that, the UTM Universal Coordinate System was assigned to the photogrammetric model based on the target points identified in the images as control points.

Each of the control points have to be identified in as many images as be possible (Figure 6).
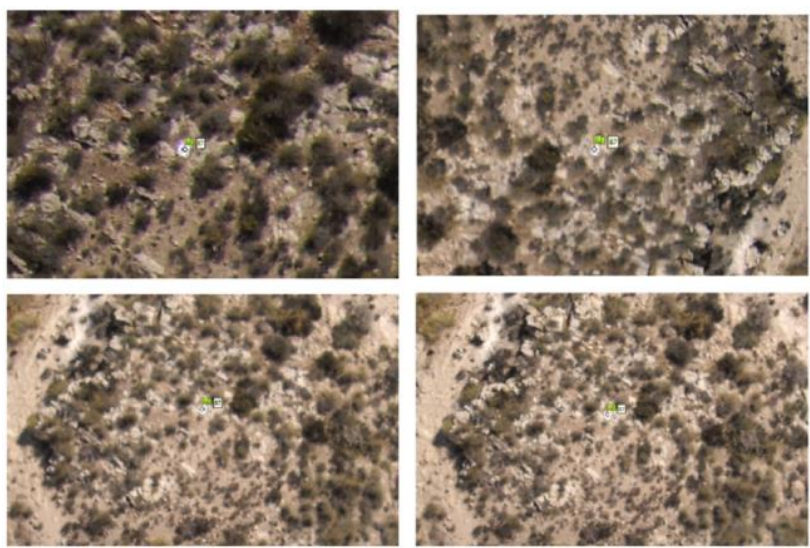

Figure 6. Identification of a control point in all the images where it appears

The accuracy of the georeferencing process depend on redundancy of identified control points and precision of identification. The number of images where each of the 33 control points were identified oscillated between 3 and 14 , been more than a half of control points in 11 images or more.

The distribution of the 13 control points through the study area (Figure 5) is other determinant factor on accuracy, and followed the recommendations of (Agüera-Vega et al., 2017; CarvajalRamírez et al., 2016; Martínez-Carricondo et al., 2018).

In this work the planimetric error in the georreferencing process was $0.018 \mathrm{~m}$, altimetric error was $0.016 \mathrm{~m}$ and total error was $0.024 \mathrm{~m}$.

Distributed through the terrain, a dense point cloud was obtained with 31 million points that, after filtering and edition, were converted to a Triangular Irregular Network (TIN) of more than 1 million vertices and 2 million textured facets and representing the altered terrain surface (Figure 7). 


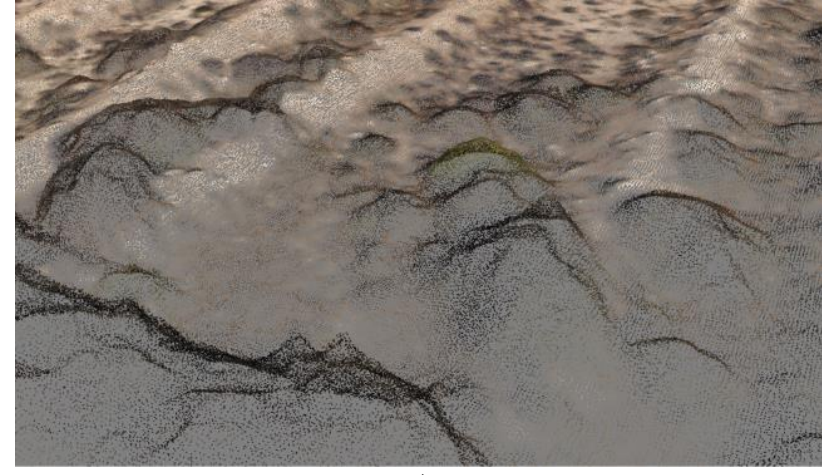

a)

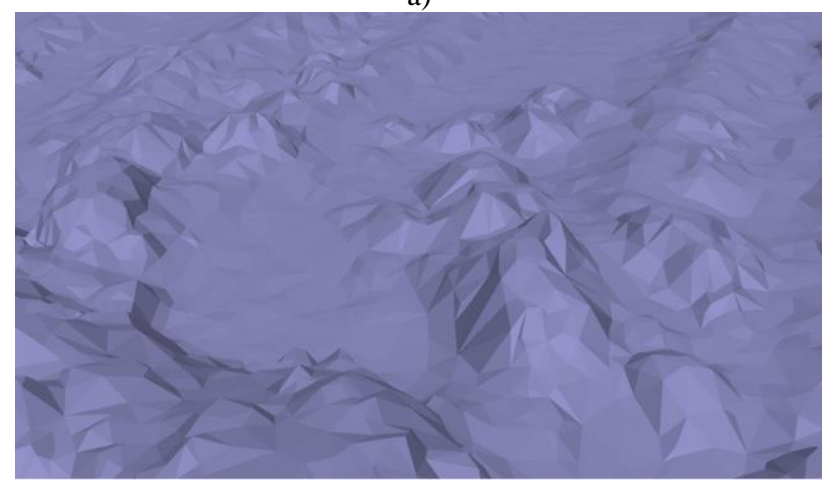

b)

Figure 7. Perspective of a detail of the area study a) dense point cloud b) TIN surface

Based on the TIN surface, a DEM was interpolated using the radial basis function method, obtaining a $0.037 \mathrm{~m}$ grid resolution and a point density of 722.6 points per $\mathrm{m}^{2}$ (Figure 8 ).

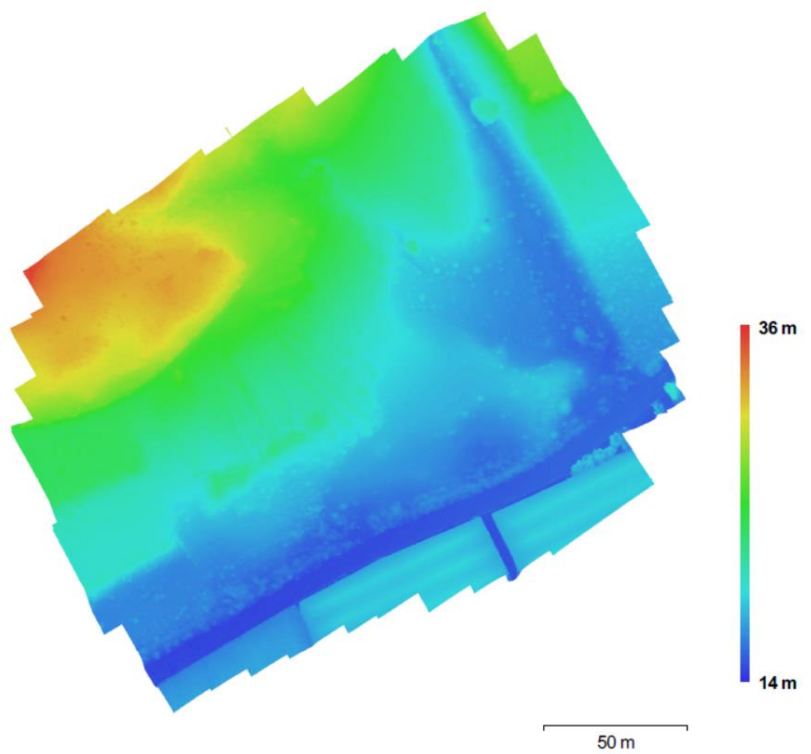

Figure 8. Reconstructed DEM of the damaged archaeological site

Finally, an orthoimage was obtained (Figure 9) by projection of the DSM and interpolation to the UTM coordinate system, applying the nearest neighbour method for missing data. The Ground Sample Distance (GSD) of the orthoimage was $0.02 \mathrm{~m}$.

\subsection{Quality control}

In order to ensure the applicability of the cartographic products in the archaeological site, a quality control was carried out comparing the coordinates of 33 check points measured in the surveying campaign with their coordinates obtained in the orthoimage.

The check points were identified in a minimum of 3 images and maximum of 14, been the half of the check points identified in more than 10 images. The planimetric error associated to identification was $0.025 \mathrm{~m}$, the altimetric was 0.026 and the total error was $0.036 \mathrm{~m}$ (0.345 pixel).

The distribution and quantity of check points was set as a sample representative of the variability in planimetry and altimetry of the site (Figure 9).

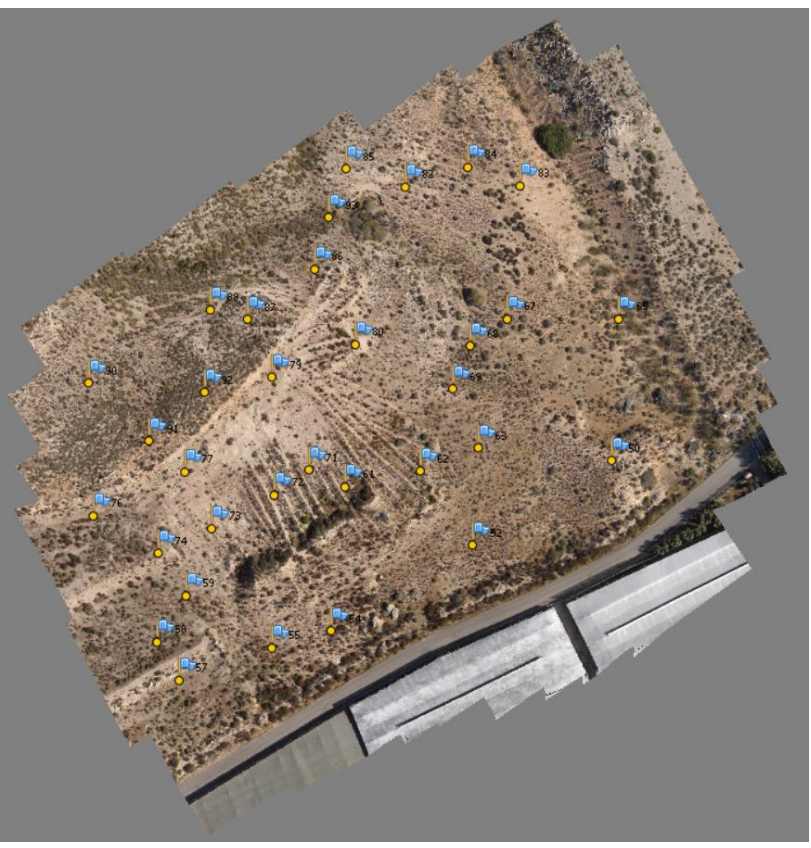

Figure 9. Check point distribution through the area study represented by flags, overlapped to de orthoimage

The selected statistic was the well-known Root Mean Square Error (RMSE) (Agüera-Vega et al., 2016), separating the planimetry RMSExy $=0.0246 \mathrm{~m}$ and altimetry $\mathrm{RMSEz}=0.0262$ m..

These results are in accord to those obtained by (Clapuyt et al., 2016; Harwin and Lucieer, 2012; James et al., 2017; Rupnik et al., 2015)

\subsection{Virtual reconstruction}

According to the archaeological precedent information, it was assumed that the certain uncontrolled works in 1994 modified the terrain and the structures of stone up to the ground level of their construction base. Hence, once the base terrain was represented by both DEM and orthoimage, a new surface was interpolated in those zones with evidences of alteration, to represent the unaltered surface. A new TIN was obtained with the Delaunay triangulation method, resulting an average slope close to $13 \%$. This morphology matches the description of the site before works.

By other hand, one of the structure of stone was modelled, parametrized and rendered including the structure, vault and channel connection, using the 3D tools available in AutoCad v. 2019 (Autodesk, 2018) (Figure 10). 


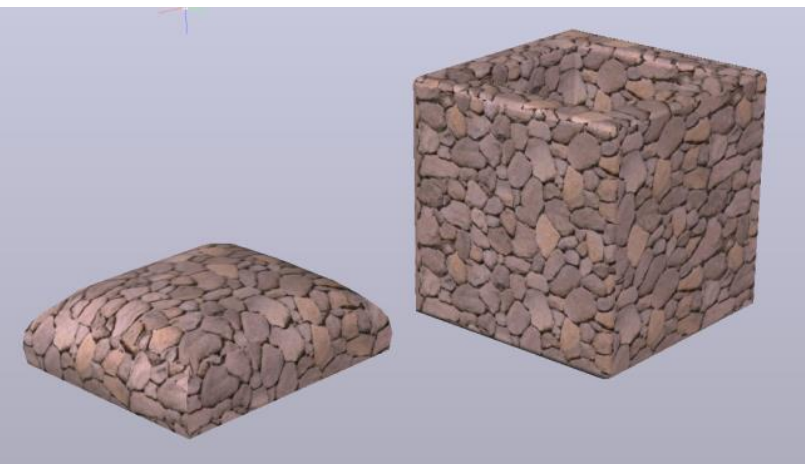

Figure 10. Model of a structure of stone and vault

The resulting virtual 3D-model integration included an interpolated surface of the unaltered terrain with 13 of the original structures made of stone, distributed in five levels, the channel network that interconnects the structures and the vaults of all of them. The high of the structures was defined between the bottom corresponding to the unaltered surface of the terrain and the top corresponding to the surface modelled by UAVphotogrammetry. Structures, channels and vaults were textured of limestones engaged with mud. This result was shared with the scientific community through Google Earth environ, organized in five layers corresponding to base terrain, unaltered terrain, structures of stone, vaults and connection layers (Figure 11).

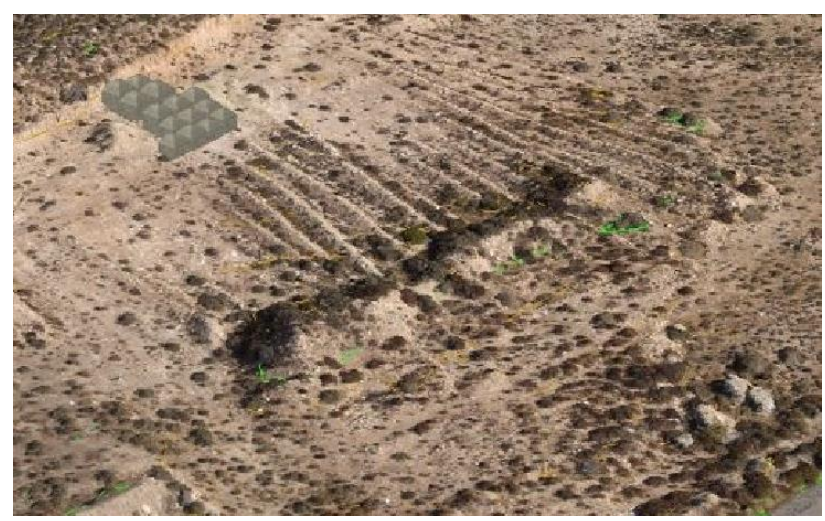

Figure 11. Augmented reality model on the Google Earth environ

\section{CONCLUSIONS}

The applied methodology in this work is adequate for an accurate representation of the terrain with virtual reconstruction of Cortijo Nuevo archaeological site purposes. The geometric error in dense point cloud, DEM and orthoimage were $\mathrm{RMSE}_{\mathrm{xy}}=0.0246 \mathrm{~m}$, $\mathrm{RMSE}_{\mathrm{z}}=0.0262 \mathrm{~m}$ and the total error sum of $0.0359 \mathrm{~m}$. According to the accuracy obtained, the representation of the study area was possible, before and after uncontrolled works that produced evident damages.

The integration of virtual models of the structures of stone in their original environ, according to the previous information recorded by archaeologists in two campaigns, lets the reconstruction and conservation of the heritage and cultural knowledge about Cortijo Nuevo, and it sharing with the scientific community.

Unfortunately, at the time to write this work, the archaeological site has suffered new unauthorized alterations and is almost destroyed.

\section{ACKNOWLEDGEMENTS}

This work was funded by "Asociación Luis Siret de Amigos y Amigas del Museo de Almería" grant number PS-OTRI-UAL2012.

\section{REFERENCES}

Achille, C., Adami, A., Chiarini, S., Cremonesi, S., Fassi, F., Fregonese, L., Taffurelli, L., 2015. UAV-based photogrammetry and integrated technologies for architectural applicationsmethodological strategies for the after-quake survey of vertical structures in Mantua (Italy). Sensors (Switzerland) 15(7), pp. 15520-15539. https://doi.org/10.3390/s150715520

Agisoft, 2018. Agisoft PhotoScan is a stand-alone software product that performs photogrammetric processing of digital images and generates 3D spatial data. http://www.agisoft.com/ (5 march 2018).

Agüera-Vega, F., Carvajal-Ramírez, F., Martínez-Carricondo, P., 2017. Assessment of photogrammetric mapping accuracy based on variation ground control points number using unmanned aerial vehicle. Meas. J. Int. Meas. Confed. 98, pp. 221-227. https://doi.org/10.1016/j.measurement.2016.12.002

Agüera-Vega, F., Carvajal-Ramírez, F., Martínez-Carricondo, P.J., 2016. Accuracy of Digital Surface Models and Orthophotos Derived from Unmanned Aerial Vehicle Photogrammetry. J. Surv. Eng. 143(2), pp. 1-10. https://doi.org/http://dx.doi.org/10.1061/(ASCE)SU.19435428.0000206

Autodesk, 2018. AutoCAD. CAD software for anyone, anywhere, anytime

https://www.autodesk.com/products/autocad/overview (5 march 2018).

Carvajal-Ramírez, F., Agüera-Vega, F., Martínez-Carricondo, P.J., 2016. Effects of image orientation and ground control points distribution on unmanned aerial vehicle photogrammetry projects on a road cut slope. J. Appl. Remote Sens. 10(3), pp. 034004. https://doi.org/10.1117/1.JRS.10.034004

Carvajal-Ramírez, F., Navarro-Ortega, A.D., Agüera-Vega, F., Martínez-Carricondo, P., Mancini, F., 2019. Virtual reconstruction of damaged archaeological sites based on Unmanned Aerial Vehicle Photogrammetry and 3D modelling . Study case of a southeastern Iberia production area in the Bronze Age. Meas. J. Int. Meas. Confed. 136, pp. 225-236. https://doi.org/10.1016/j.measurement.2018.12.092

Chiabrando, F., Nex, F., Piatti, D., Rinaudo, F., 2011. UAV and RPV systems for photogrammetric surveys in archaelogical areas: Two tests in the Piedmont region (Italy). J. Archaeol. Sci. 38(3), pp. 697-710. https://doi.org/10.1016/j.jas.2010.10.022

Clapuyt, F., Vanacker, V., Van Oost, K., 2016. Reproducibility of UAV-based earth topography reconstructions based on Structure-from-Motion algorithms. Geomorphology 260, pp. 4 15. https://doi.org/10.1016/j.geomorph.2015.05.011

De Reu, J., Plets, G., Verhoeven, G., De Smedt, P., Bats, M., Cherretté, B., De Maeyer, W., Deconynck, J., Herremans, D., Laloo, P., Van Meirvenne, M., De Clercq, W., 2013. Towards a three-dimensional cost-effective registration of the archaeological heritage. J. Archaeol. Sci. 40(2), pp. 1108-1121. https://doi.org/10.1016/j.jas.2012.08.040

Eisenbeiß, H., 2009. UAV photogrammetry, Institute of Photogrammetry and Remote Sensing, Zurich. https://doi.org/doi:10.3929/ethz-a-005939264 
Fonstad, M.A., Dietrich, J.T., Courville, B.C., Jensen, J.L., Carbonneau, P.E., 2013. Topographic structure from motion: A new development in photogrammetric measurement. Earth Surf. Process. Landforms 38(4), pp. 421-430. https://doi.org/10.1002/esp.3366

Furukawa, Y., Ponce, J., 2010. Accurate, Dense, and Robust Multiview Stereopsis. IEEE Trans. Pattern Anal. Mach. Intell. 32(8), pp. 1362-1376. https://doi.org/10.1109/TPAMI.2009.161

Galea, A., Cabrera, L., Otero, M.A., 1977. Yac. Arqueológico Fuente Amarguilla, Término Municipal Almería, Unpublished. Almería, Spain.

Gusi, F., Lujan, J., Barrachina, A., Aguilella, G., 2010. Aproximación al estudio del poblamiento litoral-costero durante la edad del bronce en la fachada oriental de la península Ibérica y del Mediodia francés. Quad. Preh. Arq. Cast 28.

Harwin, S., Lucieer, A., 2012. Assessing the Accuracy of Georeferenced Point Clouds Produced via Multi-View Stereopsis from Unmanned Aerial Vehicle (UAV) Imagery. Remote Sens. 4(6), pp. 1573-1599. https://doi.org/10.3390/rs4061573

Hendrickx, M., Gheyle, W., Bonne, J., Bourgeois, J., de Wulf, A., Goossens, R., 2011. The use of stereoscopic images taken from a microdrone for the documentation of heritage - An example from the Tuekta burial mounds in the Russian Altay. $J$. Archaeol. Sci. 38(11), pp. 2968-2978. https://doi.org/10.1016/j.jas.2011.06.013

James, M.R., Robson, S., D'Oleire-Oltmanns, S., Niethammer, U., 2017. Optimising UAV topographic surveys processed with structure-from-motion: Ground control quality, quantity and bundle adjustment. Geomorphology 280, pp. 51-66. https://doi.org/10.1016/j.geomorph.2016.11.021

Martínez-Carricondo, P., Agüera-Vega, F., Carvajal-Ramírez, F., Mesas-Carrascosa, F.-J., García-Ferrer, A., Pérez-Porras, F.-J., 2018. Assessment of UAV-photogrammetric mapping accuracy based on variation of ground control points. Int. J. Appl. Earth Obs. Geoinf. $\quad 72$, pp. $1-10$. https://doi.org/10.1016/j.jag.2018.05.015

Martínez-Carricondo, P., Carvajal-Ramírez, F., Yero-Paneque, L., Agüera-Vega, F., 2019. Combination of nadiral and oblique UAV photogrammetry and HBIM for the virtual reconstruction of cultural heritage. Case study of Cortijo del Fraile in Níjar, Almería (Spain). Build. Res. Inf. 0(0), pp. 1-20. https://doi.org/10.1080/09613218.2019.1626213

Mesas-Carrascosa, F.J., García, M.D.N., De Larriva, J.E.M., García-Ferrer, A., 2016. An analysis of the influence of flight parameters in the generation of unmanned aerial vehicle (UAV) orthomosaicks to survey archaeological areas. Sensors (Switzerland) 16(11). https://doi.org/10.3390/s16111838

Microdrones, G., 2018. Microdrones Industry - Leadding Commercial UAVs http://www.microdrones.com/ (5 march 2018)

Mozas-Calvache, A.T., Pérez-García, J.L., Cardenal-Escarcena, F.J., Mata-Castro, E., Delgado-García, J., 2012. Method for photogrammetric surveying of archaeological sites with light aerial platforms. J. Archaeol. Sci. 39(2), pp. 521-530. https://doi.org/10.1016/j.jas.2011.10.007

Ortiz, J., Gil, M.L., Martínez, S., Rego, T., Meijide, G., 2013. Three-dimensional modelling of archaeological sites using closerange automatic correlation photogrammetry and low-altitude imagery. Archaeol. Prospect. 20(3), pp. 205-217. https://doi.org/10.1002/arp.1457
Perez, M., Aguera, F., Carvajal, F., 2011. Digital Camera Calibration Using Images Taken From an Unmanned Aerial Vehicle. Int. Arch. Photogramm. Remote Sens. Spat. Inf. Sci. XXXVIII-1/(September), pp. 167-171.

Rupnik, E., Nex, F., Toschi, I., Remondino, F., 2015. Aerial multi-camera systems: Accuracy and block triangulation issues. ISPRS J. Photogramm. Remote Sens. 101(60), pp. 233-246. https://doi.org/10.1016/j.isprsjprs.2014.12.020

Sauerbier, M., Eisenbeiss, H., 2010. Uavs for the Documentation of Archaeological Excavations. Proc. Isprs Comm. V Mid-Term Symp. Close Range Image Meas. Tech. 38(5), pp. 526-531.

Trimble-Inc., 2018. Trimble, Transforming the way the world works http://www.trimble.com/ (5 march 2018).

Verhoeven, G.J.J., 2009. Providing an archaeological bird's-eye view - An overall pictureof ground-based meansto execute lowaltitude aerial photography (LAAP) in archaeology. Archaeol. Prospect. 16(4), pp. 233-249. https://doi.org/10.1002/arp.354

Verhoeven, G.J.J., Loenders, J., Vermeulen, F., Docter, R., 2009. Helikite aerial photography - A versatile means of unmanned, radio controlled, low-altitude aerial archaeology. Archaeol. Prospect. 16(2), pp. 125-138. https://doi.org/10.1002/arp.353

Wolf, P.R., Dewitt, B.A., 2014. Elements of Photogrammetry with Application in GIS, 4th ed. McGraw-Hill Education, Ney York. 